\title{
Numerical simulation for determination of limit strains of a cold rolled and solution treated Nimonic C-263 alloy sheet
}

\author{
K ANKAMMA ${ }^{1}$, P V R RAVINDRA REDDY ${ }^{2}$, S NAGARJUNA ${ }^{3}$, G CHANDRA MOHAN REDDY ${ }^{1}$, \\ M KOMARAIAH ${ }^{4}$ and N ESWARA PRASAD* \\ Regional Centre for Military Airworthiness (Materials), PO Kanchanbagh, Hyderabad 500 058, India \\ ${ }^{1}$ Mechanical Engineering Department, Mahatma Gandhi Institute of Technology, Hyderabad 500 075, India \\ ${ }^{2}$ Mechanical Engineering Department, Chaitanya Bharathi Institute of Technology, Hyderabad 500 075, India \\ ${ }^{3}$ Defence Metallurgical Research Laboratory, PO Kanchanbagh, Hyderabad 500 058, India \\ ${ }^{4}$ Malla Reddy College of Engineering and Technology, Hakimpet Post, Secunderabad 500 014, India
}

MS received 18 August 2010; revised 11 January 2011

\begin{abstract}
Nimonic alloys are Ni-base superalloys used for several high temperature applications, notable among them are the components in space vehicles, rocket engines, submarines, nuclear reactors, chemical processing vessels and heat exchange tubing as they exhibit excellent mechanical strength and creep resistance at high temperatures. Hence, evaluation of their formability characteristics is of utmost importance to make them into several useful components. Limit strains or forming limit curve is one of the parameters that indicates the formability, especially the drawability of sheet metal for deep drawing applications. In this paper, the limit strains of Nimonic C-263 alloy is investigated and presented using an explicit finite element code LSDYNA 3D. The material properties and the material model are evaluated by conducting tensile tests. The limit strains obtained from the simulation are verified by the analytical equations developed using vertex theory. The results tally within $\pm 10 \%$ error.
\end{abstract}

Keywords. Nimonic C-263 alloy; microstructure; texture; tensile deformation; limit strains.

\section{Introduction}

Superalloys exhibit excellent mechanical strength and creep resistance at high temperatures, in addition to good surface stability, phase stability as well as high oxidation and corrosion resistance. Hence, they have been used in several high temperature applications such as gas turbine blades and vanes and hot end structures of thermal protection systems (Donachie 1984; Sims et al 1987; Bradley 1988; Mclean et al 1995; Richard and Richard 2006). Some of the typical alloying elements in these Ni-based superalloys are: $\mathrm{Cr}, \mathrm{Al}, \mathrm{Ti}$, $\mathrm{Mo}, \mathrm{W}, \mathrm{Nb}$, Ta and $\mathrm{Co}$ and each of these alloying elements has a specific role in improving the properties as well as processing capability. Some of the typical alloys produced commercially are: Inconel, Hastelloy, Waspaloy, Rene alloys, Haynes alloys, MP98T, TMS alloys and finally, the CMSX single crystal alloys. Among the established Ni-based alloys, Nimonic C-263 is gaining wide acceptability as cold rolled sheet product for a number of high temperature applications.

Forming limit diagrams (FLDs) introduced by Keeler and Backofen (1964) describe the ultimate strains to which a material can be deformed prior to failure. These diagrams are extensively used to define the onset of plastic instability in sheet metal working processes that exhibit a plane state of

*Author for correspondence (nep@ cemilac.drdo.in) stress (Boudeau and Gelin 1992; Gronostajski and Zimniak 1995; Atkins 1996). The experimental methods for determining FLDs are well established, by stretching the sheet over a hemispherical punch or using a circular punch with a flat bottom in Marciniak cup test (Marciniak and Kuczynski 1967).

In Marciniak cup test, the forming limit curves are obtained by etching circular grids on the blanks of various widths to produce varying strain states from uniaxial condition to biaxial condition. Simulations can also be carried out in the same manner. Since all the strain states are not relevant to deep drawing and moreover the tests generally carried out are relevant to stretch forming and stamping, a different method is tried in the present work and compared with the analytical solution based on the Vertex theory. The principal strain values, where nodal effective stress crosses the UTS (true stress) of the material are taken as limit stains and plotted to get the forming limit curves.

\section{Experimental}

\subsection{Sheet material}

The Nimonic C-263 alloy sheet used in the present investigation was procured from Misra Dhatu Nigam (MIDHANI), Hyderabad, India. The as-received material was in the form 
Table 1. Chemical composition of experimental alloy.

\begin{tabular}{lccccccccccc}
\hline Element & $\mathrm{C}$ & $\mathrm{Co}$ & $\mathrm{Cr}$ & $\mathrm{Mo}$ & $\mathrm{Al}$ & $\mathrm{Si}$ & $\mathrm{Ti}$ & $\mathrm{Mn}$ & $\mathrm{B}$ & $\mathrm{P}$ & $\mathrm{Ni}$ \\
\hline Composition (wt. \%) & 0.045 & 19.01 & 19.79 & 6.01 & 0.5 & 0.04 & 2.1 & 0.42 & 0.002 & 0.005 & Bal. \\
\hline
\end{tabular}

Table 2. Details of tensile test specimen.

\begin{tabular}{lccccc}
\hline & & \multicolumn{3}{c}{ Specimen geometry employed } \\
\cline { 3 - 6 } $\begin{array}{l}\text { Alloy } \\
\text { designation }\end{array}$ & $\begin{array}{c}\text { Directions } \\
\text { studied }\end{array}$ & $\begin{array}{c}\text { Type of } \\
\text { specimen }\end{array}$ & $\begin{array}{c}\text { Thickness } \\
(\mathrm{mm})\end{array}$ & $\begin{array}{c}\text { Width } \\
(\mathrm{mm})\end{array}$ & $\begin{array}{c}\text { Gauge length } \\
(\mathrm{mm})\end{array}$ \\
\hline Nimonic C-263 & $\begin{array}{c}\mathrm{L}, \mathrm{L}+30^{\circ}, \mathrm{L}+45^{\circ} \\
\mathrm{L}+60^{\circ}, \mathrm{LT}\end{array}$ & Flat & 1 & 6 & 25 \\
\hline
\end{tabular}

of cold rolled and solution treated sheet of thickness $1.0 \mathrm{~mm}$. Cold rolling was done using a 6-high single strand roll mill. The cold rolled sheet was solution treated at $1150 \pm 10^{\circ} \mathrm{C}$ for 5-15 min, followed by air cooling. The nominal composition of the alloy is given in table 1 .

\subsection{Tensile property evaluation}

In-plane anisotropy in tensile properties has been determined by means of tests conducted on specimens oriented differently with respect to the rolling direction. The details of the alloy studied and specimen geometries employed are given in table 2.

The properties evaluated include the $0.2 \%$ yield stress (YS), the ultimate tensile stress (UTS), elongation (total plastic strain to fracture), the uniform strain $\left(\varepsilon_{u}\right)$ and the work hardening exponent $(n)$ using Hollomon equation:

$$
\sigma=K \varepsilon_{\mathrm{p}}^{n}
$$

where $\sigma$ is the true stress, $K$ the strength coefficient, $\varepsilon_{\mathrm{p}}$ the true plastic strain and ' $n$ ' the work hardening exponent. The tests were conducted as per the ASTM Standard E-8 (2004). Fractographical features of tensile tested specimens were observed in a scanning electron microscope.

\section{Results and discussion}

\subsection{Microstructure and texture}

Figure 1 shows the microstructure of the alloy sheet in the asreceived solution treated condition. It principally consists of partially recrystallized, equi-axed grains in the rolling plane (RP) and unrecrystallized grains in through-thickness (TT) plane with high density of annealing twins in both RP and TT planes. The average grain size is $\sim 30 \mu \mathrm{m}$. The XRD pattern of cold rolled and solution treated specimen (figure 2) shows the change in intensity ratios from that of powder pattern indicating the presence of crystallographic texture. Figure 3(a) shows the $\varphi_{2}$ section of orientation distribution

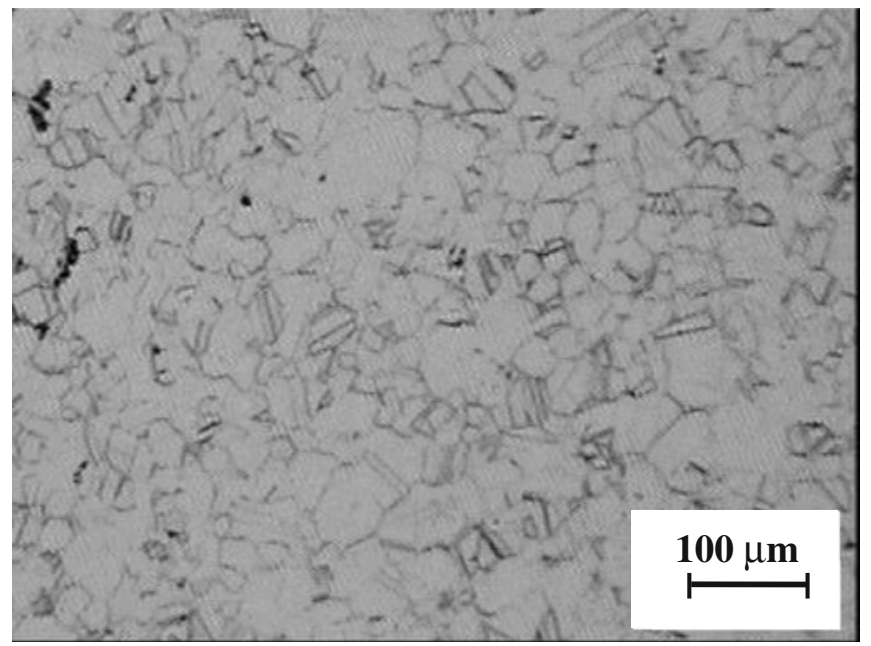

Figure 1. Optical micrograph of cold rolled Nimonic C-263 alloy sheet in solution treated condition.

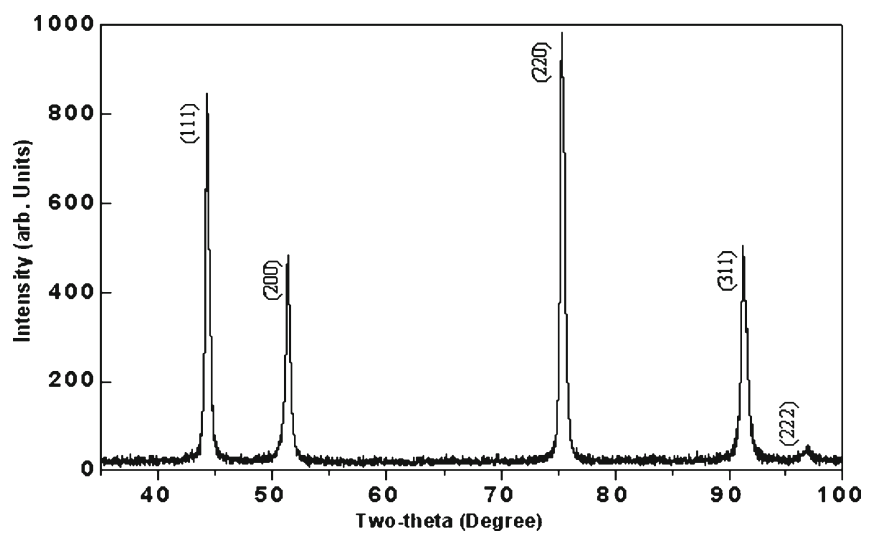

Figure 2. XRD pattern of cold rolled Nimonic C-263 alloy sheet in solution treated condition.

function (ODF) plot, and the corresponding pole figures of (111) and (200) orientations are shown in figure 3(b). The data in figures 3(a) and (b) show that the overall texture 
is weak and $\{111\}$ and $\{200\}$ pole figures reveal several components with low intensity. The $\varphi_{2}$ section of corresponding ODF, shown in figure 3(a), exhibits the presence of $\{011\}\langle 211\rangle[f(g)=2 \cdot 3],\left\{\begin{array}{lll}1 & 1 & 15\end{array}\right\}\langle 110\rangle[f(g)=2 \cdot 2]$, $\{110\}\langle 110\rangle[f(g)=2 \cdot 0],\{112\}\langle 021\rangle[f(g)=2 \cdot 2]$ and $\{225\}\langle 110\rangle[f(g)=1.6]$ major texture components. The texture component $\left\{\begin{array}{lll}1 & 1 & 15\end{array}\right\}$ is $5^{\circ}$ away from $\{001\}\langle 110\rangle$ component. It is to be noted that both the $\{011\}\langle 211\rangle$ and $\{001\}\langle 110\rangle$ components have been reported in recrystallized $f c c$ metals and alloys (Singh et al 1998). The presence of $\left\{\begin{array}{lll}1 & 1 & 15\end{array}\right\}\langle 110\rangle$ component thus indicates that solution treatment after cold rolling has not produced stable end orientation.

\subsection{Tensile deformation and fracture behaviour}

The tensile data determined from the testing of specimens oriented differently with respect to the rolling direction are given in table 3 . The data in table 3 show, despite the weak crystallographic texture, the Nimonic C-263 alloy sheet exhibits significant anisotropy in tensile properties. This is graphically shown in figure 4 . As the orientation changes from 0 to $90^{\circ}$, the yield strength and ultimate tensile strength (UTS) decrease gradually. On the other hand, the ductility and uniform strain increase from 0 to $60^{\circ}$ and then decreases from $60^{\circ}$ to $90^{\circ}$. Unlike the variation in strength properties (YS and UTS) and inline with variation in uniform elongation and ductility (total plastic strain to fracture), the value of $n$ increases with orientation up to $60^{\circ}$ and then decrease. On the other hand, the ratio of UTS to YS shows a reverse trend. However, it should be noted that the variation in properties ( $n$ and UTS/YS) is significantly less as compared to the other commonly used tensile properties (YS, UTS, total elongation and uniform elongation). The variation in the work hardening characteristics, in terms of $n$, the work hardening exponent and the ratio of ultimate tensile to yield strength values are also shown in figure 4.

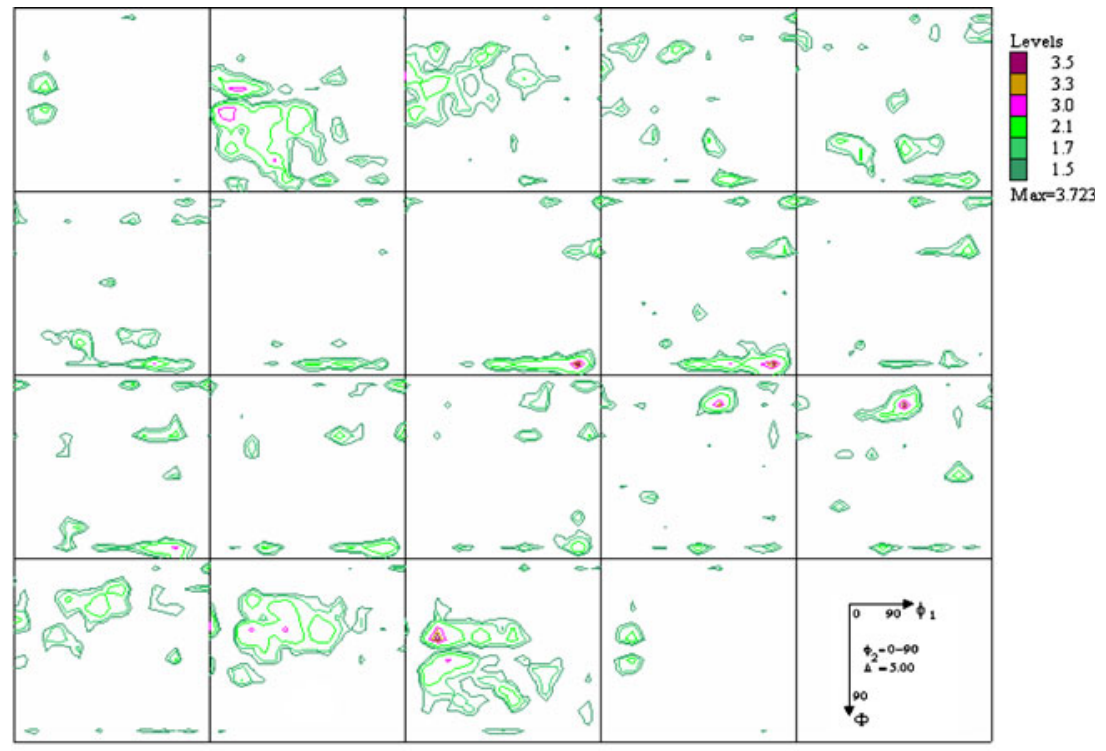

(a)

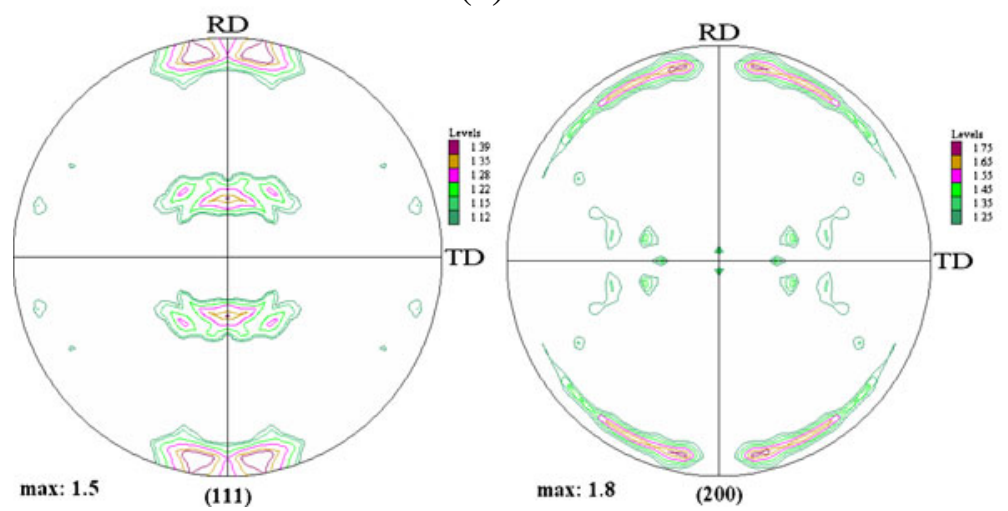

(b)

Figure 3. (a) $\varphi_{2}$ section of the ODF plot and (b) pole figures of (111) and (200), of the alloy of $1.0 \mathrm{~mm}$ thickness in the as-received, cold rolled and solution treated condition. 
Table 3. Anisotropy in tensile properties of Nimonic C-263 alloy sheet of $1.0 \mathrm{~mm}$ thickness in the as-received, cold rolled and solution treated condition (Tests were conducted at room temperature with an initial strain rate of $10^{-4} \mathrm{~s}^{-1}$ ).

\begin{tabular}{lccccc}
\hline & \multicolumn{4}{c}{ Specimen orientation with respect to rolling direction (Deg) } \\
\cline { 2 - 6 } Property & $L$ & $L+30^{\circ}$ & $L+45^{\circ}$ & $L+60^{\circ}$ & $L T$ \\
\hline $\begin{array}{l}\text { 0.2\% Y.S (MPa) } \\
\text { UTS (MPa) }\end{array}$ & 556 & 489 & 484 & 485 & 460 \\
Total elongation (\%) & 963 & 847 & 845 & 780 & 808 \\
$\quad(25$ mm gauge length) & $30 \cdot 6$ & 51 & 53.4 & $53 \cdot 2$ & 41.8 \\
Uniform strain $\left(\varepsilon_{u}\right)$ & 0.28 & 0.43 & 0.45 & 0.48 & 0.39 \\
Work hardening exponent $(n)$ & 0.39 & 0.38 & 0.43 & 0.40 & 0.39 \\
\hline
\end{tabular}
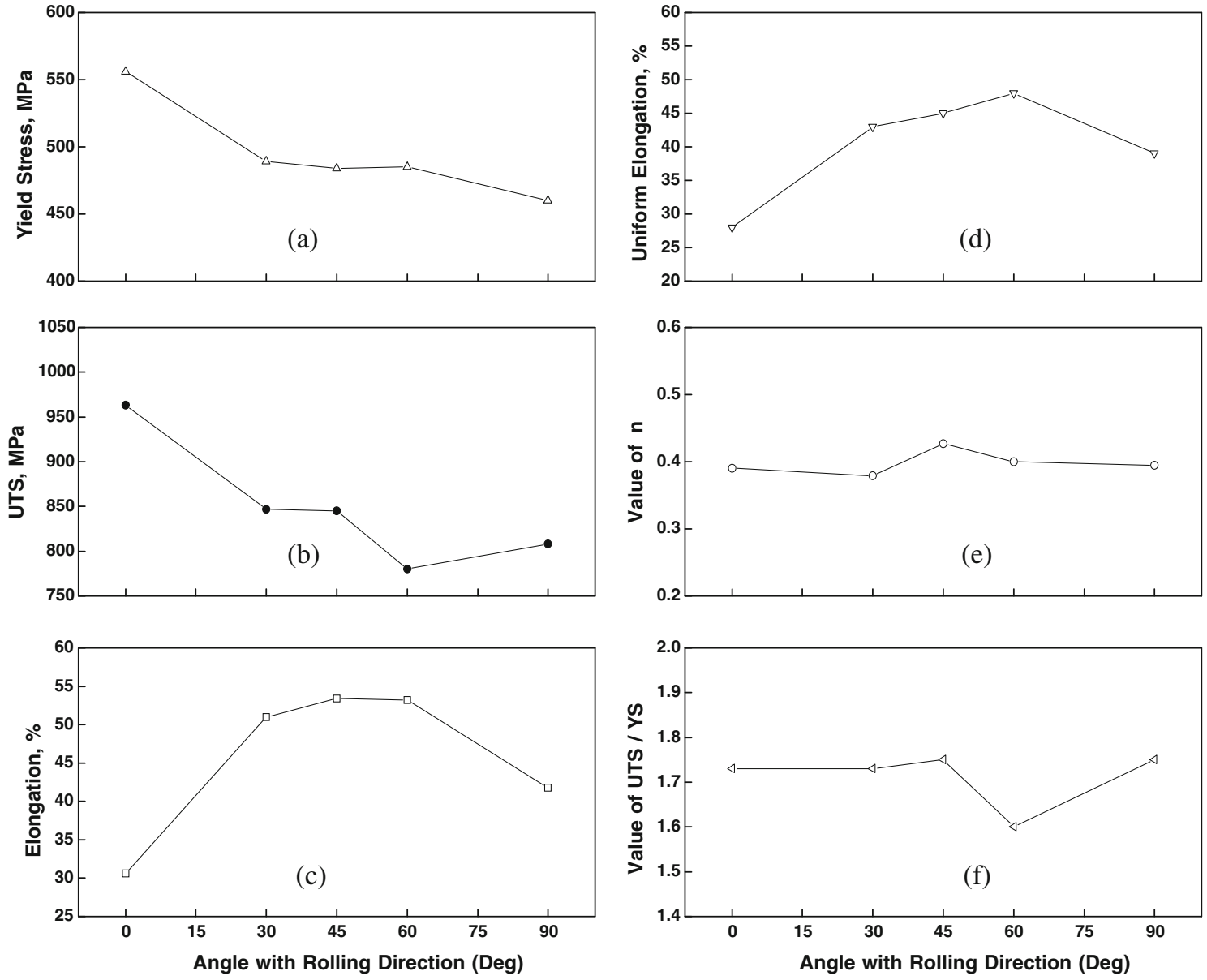

Figure 4. Anisotropy in tensile properties of cold rolled and solution treated Nimonic C-263 alloy sheet, showing the variation with respect to rolling direction in (a) $0 \cdot 2 \%$ yield stress, (b) UTS, (c) elongation, (d) uniform elongation, (e) work hardening exponent, $n$ and (f) ratio of UTS to YS.

\subsection{Fractographic features}

The fractured surfaces of the tensile tested specimens were observed under scanning electron microscope to determine the mode of fracture. The fracture features were observed for the $1.0 \mathrm{~mm}$ thick sheet in two heat treated conditions (ST and $\mathrm{ST}+8 \mathrm{~h}$ aged).
Fractographs of the specimens (figure 5) clearly show that the alloy sheet under tensile loading fail predominantly by high energy ductile dimple fracture with a small extent of shear fracture. The dimples observed were found to be distinctly of two sizes. The coarse dimples are of average diameter of $2-5 \mu \mathrm{m}$ and their size as well as number density decrease initially as the orientation changes from 0 to $45^{\circ}$ 

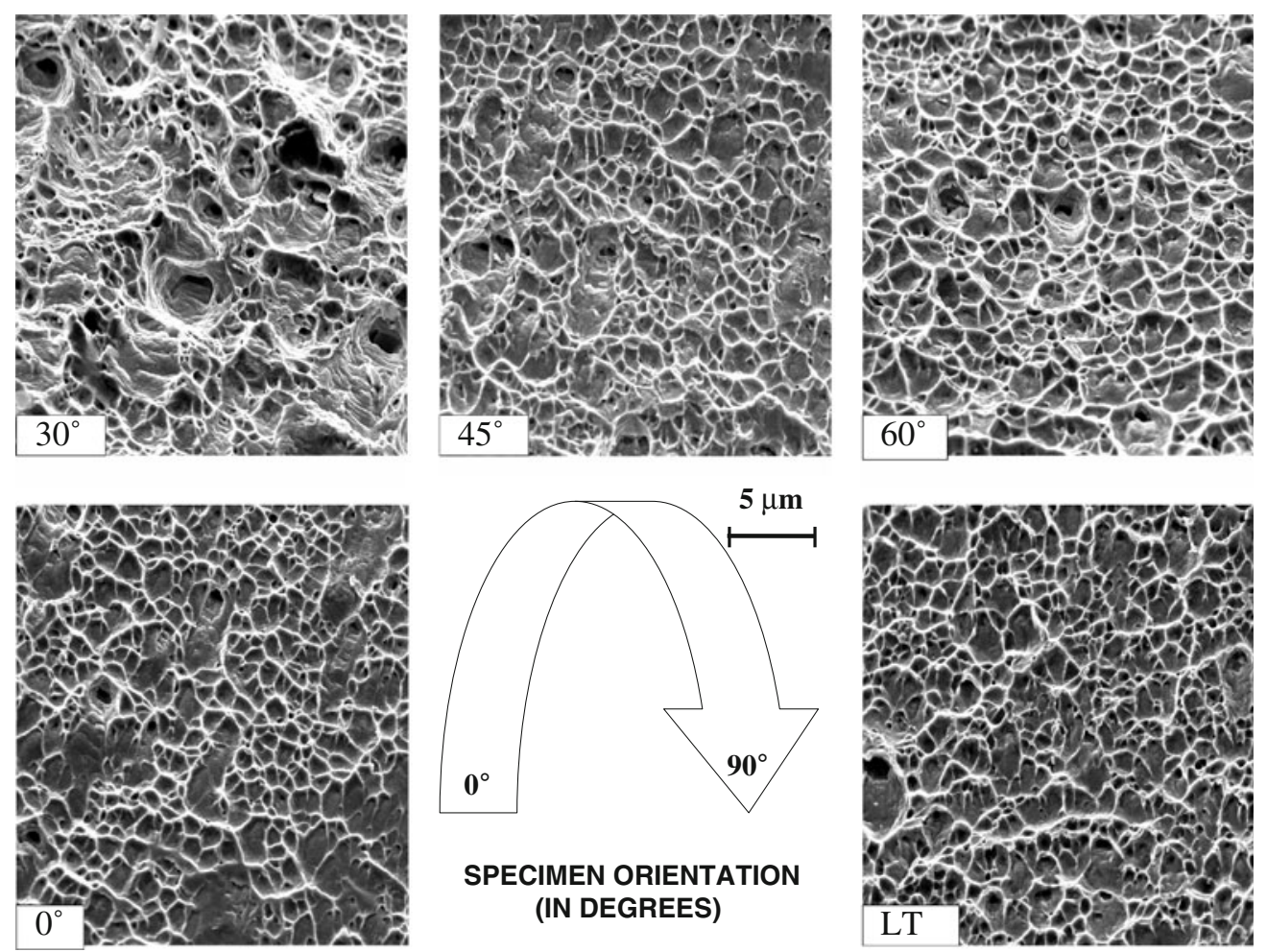

Figure 5. Fractographical features of tensile tested specimens of Nimonic C-263 alloy sheet of $1.0 \mathrm{~mm}$ thickness in different test directions.

and then increase again. On the other hand, the fine micro dimples, are found to be of similar density and size $(2-4 \mu \mathrm{m})$ in all the 5 test directions. The two size distribution of dimples (coarse and fine/micro dimples) leading to gross dimple fracture could have resulted from the void-nucleation, growth and their coalescence. The void nucleation particles presumably are large sized $\mathrm{MC} / \mathrm{M}_{23} \mathrm{C}_{6}$ carbides in case of coarse dimples (whose density and spacial distribution match well with those of the carbides) and $\gamma^{\prime}$ precipitates in case of the fine and uniformly distributed micro-dimples.

\subsection{Material model for numerical simulation}

LS DYNA 970 has 134 material models, out of which, the one where the material property data fits, is selected. The anisotropy of a sheet metal during sheet forming is a combination of the initial anisotropy due to its previous history of thermo-mechanical processing and due to the plastic deformation during forming. The former leads to symmetry with orthotropic character while the latter called as deformation induced anisotropy can destroy this symmetry when principal material symmetry and deformation axes are not superimposed. Therefore, modeling of plastic anisotropy itself and its implementation in finite element code can be complex. Moreover, the data needed to capture deformation induced anisotropy is rarely available, particularly for industrial application. For practical purposes the assumption that the change of anisotropic properties during sheet metal forming is small and negligible when compared to anisotropy induced by rolling and heat treatment, which is widely accepted. Therefore, when plastic deformation is moderate, a simple description of anisotropy based on experimental data as input might be adequately accurate for sheet metal forming simulation rather than more sophisticated anisotropy model (Yoon et al 2004). So, the material models which take the initial anisotropy into account such as Barlat's 3-parameter plasticity model (Barlat and Lian 1989), Barlat's anisotropic plasticity model (Barlat et al 1991) can be used for metal forming analysis with sufficient accuracy. Hence, Barlat's 3-parameter plasticity model is chosen for this work. The yield function $(\phi)$, used in Barlat's model is

$$
\phi=a\left|K_{1}+K_{2}\right|^{m}+a\left|K_{1}-K_{2}\right|^{m}+c\left|2 K_{2}\right|^{m}=2 \sigma_{y}^{m},
$$

where $\sigma_{y}$ is the current effective stress, $K$ the strength coefficient and the exponent ' $m$ ' is taken as 8 for $f c c$ metals (Hallquist 1998) and $K_{1}$ and $K_{2}$ are given by

$$
\begin{aligned}
& K_{1}=\frac{\sigma_{x}+h \sigma_{y}}{2}, \\
& K_{2}=\sqrt{\left(\frac{\sigma_{x}-h \sigma_{y}}{2}\right)^{2}+P^{2} \tau_{x y}^{2}},
\end{aligned}
$$


with the hardening function

$$
\sigma_{y}=K\left(\varepsilon_{\mathrm{p}}+\varepsilon_{0}\right)^{n},
$$

where $\varepsilon_{\mathrm{p}}$ is the plastic strain, $\varepsilon_{0}$ the initial yield strain and $n$ the strain hardening index.

The anisotropic material constants $a, c$ and $h$ in (1)-(4), are obtained through $R_{00}$ and $R_{90}$ as

$$
\begin{aligned}
& a=2-2 \sqrt{\frac{R_{00} R_{90}}{\left(1+R_{00}\right)\left(1+R_{90}\right)}}, \\
& c=2-a, \\
& h=\sqrt{\frac{R_{00}\left(1+R_{90}\right)}{R_{90}\left(1+R_{00}\right)}} .
\end{aligned}
$$

All the material properties required are obtained from the tensile testing as given in table 4 . The variation of true

Table 4. Material properties of Nimonic C-263 alloy.

\begin{tabular}{lll}
\hline S1. no. & \multicolumn{1}{c}{ Material property } & \multicolumn{1}{c}{ Value } \\
\hline 1. & Density & \\
2. & Young's Modulus & $8 \cdot 36 \mathrm{~g} / \mathrm{cm}^{3}$ \\
3. & Poison's ratio & $217 \cdot 25 \mathrm{GPa}$ \\
4. & Strength coefficient, $K$ & $0 \cdot 3053$ \\
5. & Strain hardening Index, $n$ & $2025 \cdot 4$ \\
6. & UTS (true stress) & $0 \cdot 35$ \\
7. & Yield strain & $1231 \mathrm{MPa}$ \\
8. & $R_{0}$ & 0.00492 \\
9. & $R_{45}$ & $2 \cdot 20$ \\
10. & $R_{90}$ & $2 \cdot 03$ \\
\hline
\end{tabular}

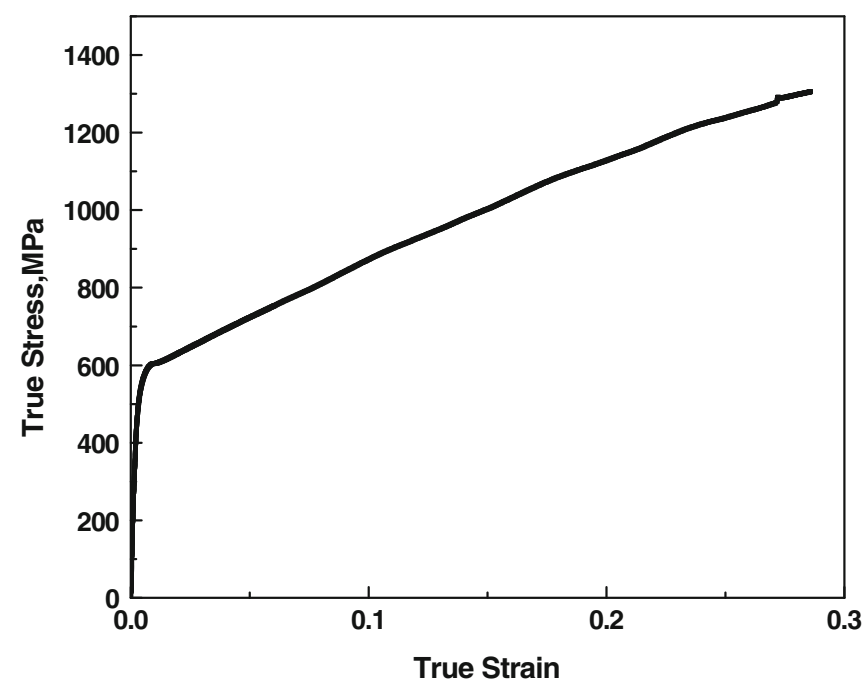

Figure 6. True strain-true stress diagram of Nimonic C-263 alloy sheet of $1.0 \mathrm{~mm}$ thickness in cold rolled and solution treated condition. stress with true strain and the true stress with true plastic strain evaluated in the process curve are shown in figures 6 and 7.

\subsection{Finite element modeling}

FEA Model was used for forming a cylindrical cup with the following tooling parameters: (i) punch diameter: $50 \mathrm{~mm}$, (ii) punch profile: $2 \mathrm{~mm}$, (iii) die profile: $3 \mathrm{~mm}$, (v) clearance: $10 \%$, friction coefficient: 0.015 and 0.20 . The finite model used in the simulation is shown in figure 8 . Based on the symmetry boundary condition, a quarter of the geometry is modeled. The punch presses the sheet into die cavity. In sheet metal forming, generally, membrane elements or

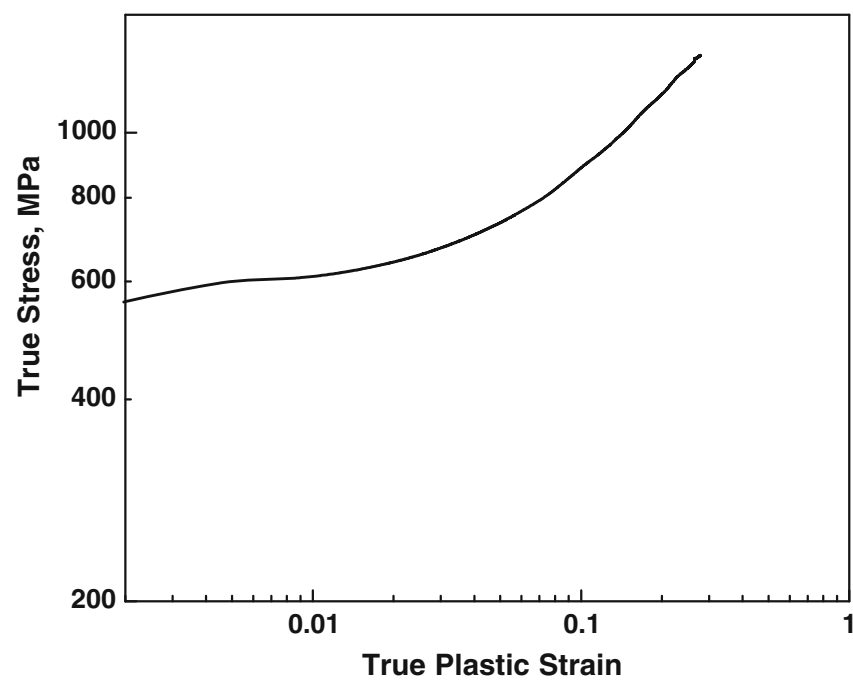

Figure 7. Plastic strain-true stress diagram of Nimonic C-263 alloy sheet of $1.0 \mathrm{~mm}$ thickness in cold rolled and solution treated condition.

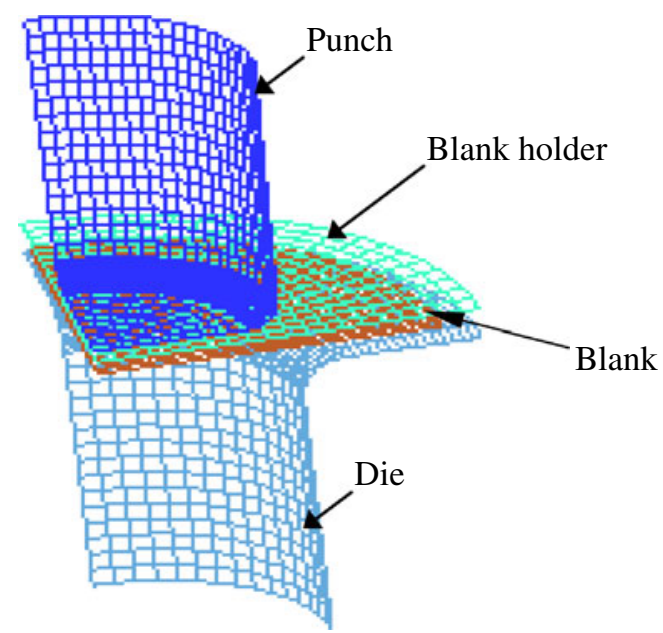

Figure 8. Finite element model. 
continuum elements or shell elements are employed (Geng and Wagoner 2002). Since membrane elements lack the bending stiffness and the continuum element takes higher computation time, the blank is modeled with shell elements at the mid plane using Belytschko et al $(1981,1984)$ formulation with five integration points. Punch, die and blank holder are taken as rigid materials.

The material model cited in $\$ 3.4$ is taken for the blank material with the properties listed in table 4 and plastic strain-true stress curve, shown in figure 7, as input. A spring loaded blank holder is assumed. Hence, a linearly varying blank holding force (BHF) scheme is taken in simulation. Initially the BHF scheme is optimized with a criterion based on the minimum BHF for wrinkle free cup formation. The optimized BHF scheme is shown in figure 9.

For any finite element analysis, the mesh convergence was also verified using $h$-method, where mesh convergence is checked by observing the convergence of punch force at various mesh sizes. Hematian (2000) studied the convergence in a similar manner earlier. Load on the punch with various mesh sizes from $2 \mathrm{~mm}$ to $0.25 \mathrm{~mm}$ is shown in figure 10 and it is evident from this graph that the load curve is almost same for $0.5 \mathrm{~mm}$ and $0.25 \mathrm{~mm}$ mesh sizes. So mesh size of

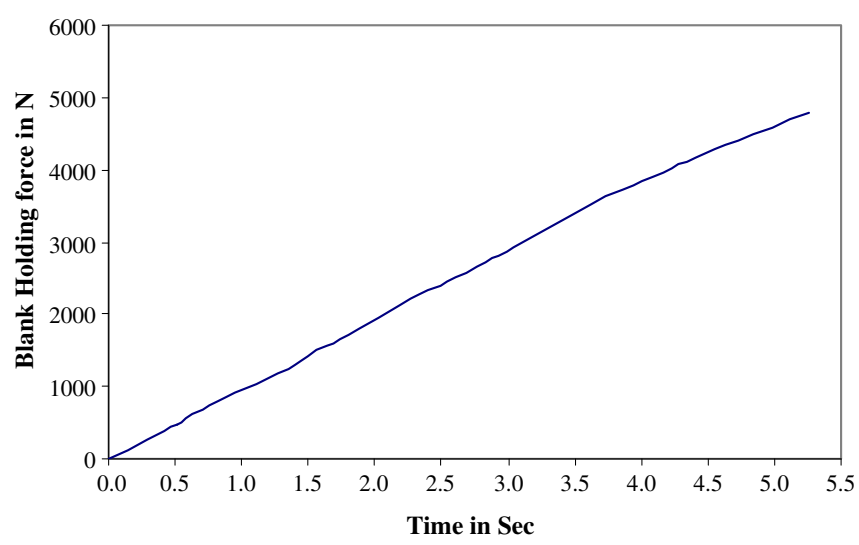

Figure 9. Optimized BHF scheme.

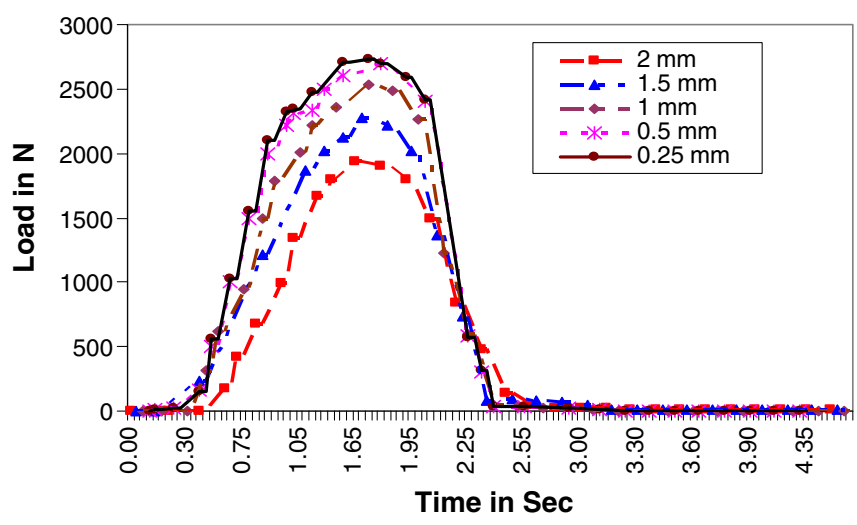

Figure 10. Punch load-time curves for various mesh sizes.
$0.5 \mathrm{~mm}$ is chosen for the analysis. Since, no failure criterion is specified with this material model. The tearing is identified manually, i.e. the failure is considered to occur when $\sigma_{\text {eff }}=\sigma_{\mathrm{UTS}}$, where $\sigma_{\text {eff }}$ and $\sigma_{\mathrm{UTS}}$ are effective stress and ultimate tensile strength, respectively.

\subsection{Simulation for determination of limit strains}

Several attempts have been made in the past where comprehensive studies have been conducted in which the influence of crystal anisotropy, texture, dislocation structure and microstructure on the forming limit diagrams (FLDs) and strain paths (Nakazima et al 1968; Kikuma and Nakazima 1971; Toth et al 1988; Wu et al 1997; Hiwatashi 1998; Savoie et al 1998; Hashiguchi and Protasov 2004; Eyckens et al 2009). Simulations are carried out iteratively to evaluate the limit strains as per the following procedure. Since, the failure criteria is not specified for the material model used in the present work, the failure cannot be seen. The cup is being drawn continuously, even after the effective stress becomes more than the UTS (true stress) of the material. So, the simulation is run till the maximum effective stress crosses the UTS and the nodal results of that state are output to a file. From the nodal results, the node numbers for which the effective stress nearer to UTS upto an accuracy of $\pm 0.2 \mathrm{MPa}$ (i.e. $1231 \pm 0.2 \mathrm{MPa}$ ) are noted down. Then nodal results of the principal strains of that state are written to another file and the principal strain values of the nodes, whose effective stress is within the range specified above are noted down. These principal strains are nothing but the limit strains. The simulation is continued till sufficient data is collected for plotting forming limit curves (FLCs) and the same is presented in figure 11 . The data in figure 11 show the regions of safe and unsafe deformation in general and drawability in particular.

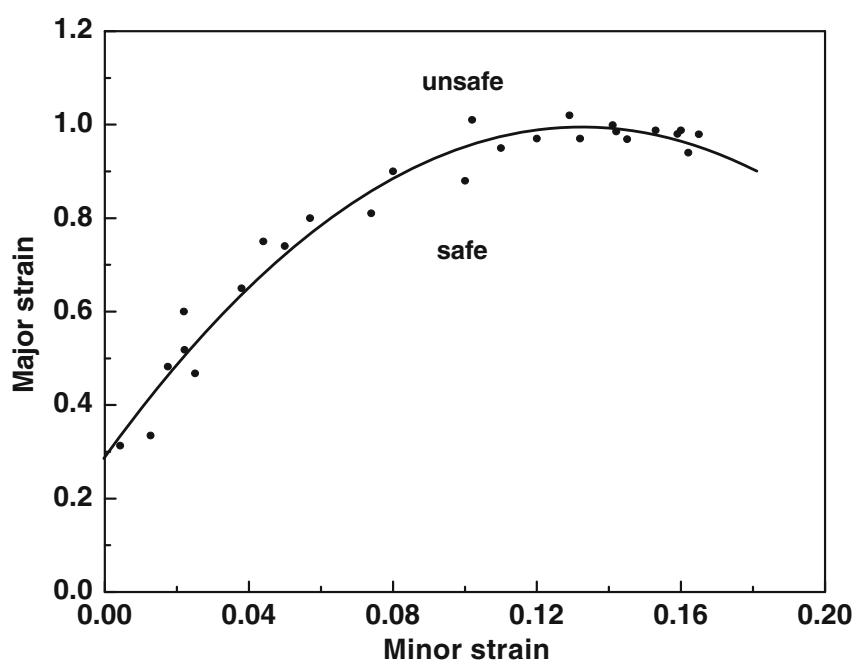

Figure 11. Forming limit curve for Nimonic C-263 alloy. 
Table 5. Comparison of ultimate strain values obtained from vertex theory and with constitutive law.

\begin{tabular}{|c|c|c|c|c|c|c|c|}
\hline Sl. no. & $\begin{array}{l}\text { Major strain } \\
\quad\left(\varepsilon_{1}\right)\end{array}$ & $\begin{array}{c}\text { Minor strain } \\
\left(\varepsilon_{2}\right)\end{array}$ & $\begin{array}{l}\text { Limiting major } \\
\text { stress }\left(\sigma_{1}\right)(\mathrm{MPa})\end{array}$ & $\begin{array}{l}\text { Limiting minor } \\
\text { stress }\left(\sigma_{2}\right)(\mathrm{MPa})\end{array}$ & $\begin{array}{l}\text { Ultimate strain } \\
\text { from (9) }\left(\varepsilon^{*}\right)\end{array}$ & Error & $\%$ Error \\
\hline 1. & $0 \cdot 313$ & $0 \cdot 00428$ & 1279 & 150 & $0 \cdot 3752$ & -0.0252 & $-7 \cdot 20$ \\
\hline 2. & 0.482 & $0 \cdot 0175$ & 1337 & 275 & $0 \cdot 3207$ & 0.0292 & $8 \cdot 36$ \\
\hline 3. & 0.98 & $0 \cdot 159$ & 1350 & 568 & $0 \cdot 3239$ & 0.0260 & $7 \cdot 44$ \\
\hline 4. & 0.988 & $0 \cdot 153$ & 1388 & 557 & 0.3349 & 0.0150 & $4 \cdot 29$ \\
\hline 5. & 0.985 & $0 \cdot 142$ & 1324 & 509 & 0.3389 & $0 \cdot 0110$ & $3 \cdot 14$ \\
\hline 6. & 0.988 & $0 \cdot 16$ & 1351 & 542 & $0 \cdot 3460$ & 0.0039 & $1 \cdot 13$ \\
\hline 7. & $1 \cdot 01$ & $0 \cdot 102$ & 1164 & 393 & $0 \cdot 3184$ & 0.0315 & $9 \cdot 02$ \\
\hline 8. & $0 \cdot 518$ & 0.0221 & 1307 & 288 & $0 \cdot 3259$ & 0.0240 & $6 \cdot 88$ \\
\hline 9. & 0.979 & $0 \cdot 165$ & 1385 & 578 & $0 \cdot 3366$ & 0.0133 & $3 \cdot 81$ \\
\hline 10. & $1 \cdot 02$ & $0 \cdot 129$ & 1364 & 499 & $0 \cdot 3322$ & 0.0177 & $5 \cdot 05$ \\
\hline 11. & 0.468 & 0.0251 & 1413 & 346 & $0 \cdot 3285$ & 0.0214 & $6 \cdot 12$ \\
\hline 12. & $0 \cdot 335$ & 0.0127 & 1403 & 295 & $0 \cdot 3201$ & 0.0298 & 8.53 \\
\hline 13. & 0.999 & $0 \cdot 141$ & 1386 & 548 & $0 \cdot 3199$ & $0 \cdot 0300$ & 8.57 \\
\hline 14. & 0.969 & $0 \cdot 145$ & 1375 & 504 & $0 \cdot 3743$ & -0.0243 & $-6 \cdot 96$ \\
\hline 15. & 0.97 & $0 \cdot 132$ & 1385 & 464 & $0 \cdot 3821$ & -0.0521 & -9.89 \\
\hline 16. & $0 \cdot 6$ & 0.022 & 1323 & 250 & $0 \cdot 3751$ & -0.0251 & $-7 \cdot 18$ \\
\hline 17. & 0.74 & 0.05 & 1388 & 349 & $0 \cdot 3783$ & -0.0283 & -8.09 \\
\hline 18. & $0 \cdot 81$ & 0.074 & 1403 & 410 & $0 \cdot 3728$ & -0.0228 & $-6 \cdot 52$ \\
\hline 19. & 0.88 & $0 \cdot 1$ & 1423 & 481 & $0 \cdot 3476$ & $0 \cdot 0023$ & 0.67 \\
\hline 20. & $0 \cdot 8$ & 0.057 & 1350 & 378 & $0 \cdot 3296$ & 0.0203 & $5 \cdot 82$ \\
\hline 21. & $0 \cdot 75$ & $0 \cdot 044$ & 1357 & 333 & $0 \cdot 3521$ & -0.0021 & -0.61 \\
\hline 22. & 0.65 & $0 \cdot 038$ & 1375 & 352 & $0 \cdot 3268$ & 0.0231 & $6 \cdot 61$ \\
\hline 23. & 0.9 & 0.08 & 1385 & 392 & $0 \cdot 3847$ & -0.0347 & -9.91 \\
\hline 24. & 0.97 & $0 \cdot 12$ & 1411 & 469 & $0 \cdot 3801$ & -0.0301 & -8.60 \\
\hline 25. & 0.95 & $0 \cdot 11$ & 1397 & 458 & $0 \cdot 3700$ & -0.0200 & $-5 \cdot 73$ \\
\hline
\end{tabular}

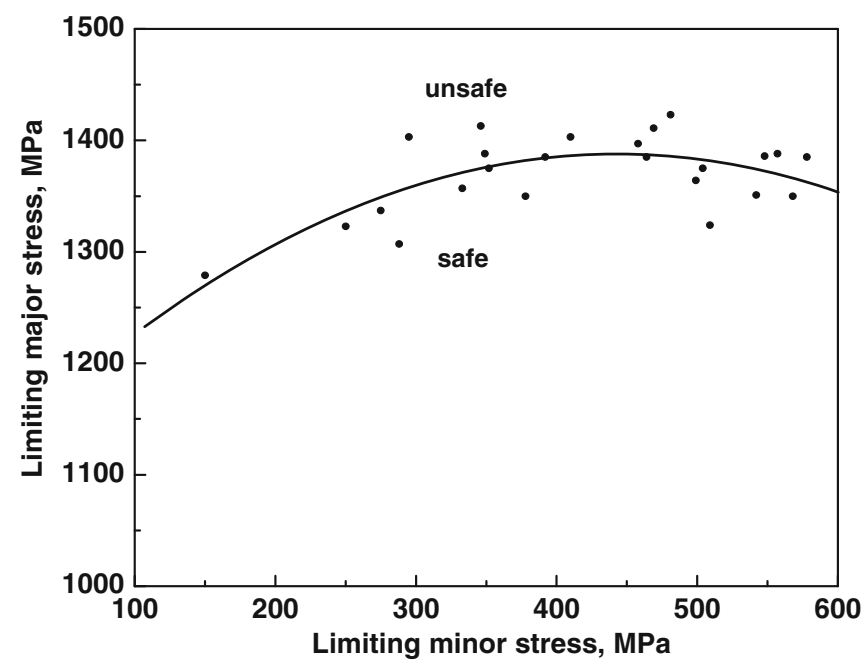

Figure 12. Forming stress limit curve for Nimonic C-263 alloy.

It is observed that the effective stress crosses UTS at the punch corner where the state of stress is biaxial tension (Dieter 2001) (considering the plane stress condition). Hence, only right hand side of FLC is obtained. Since this method of finding limit strains is proposed by the author, the method has to be validated for its correctness. The validation is carried out using the vertex theory developed by Storen and Rice (1975) and modified by Zhu et al (2001) and the forming limits are derived by Jie et al (2007) for the material with power law plasticity model with Hosford's yield criterion. The same is presented in the following equations.

For left hand side of FLD the forming limit strain is

$$
\begin{aligned}
\varepsilon^{*}= & \frac{\left(1+R_{0}\right)\left[r_{\sigma}^{a-2}+R_{90}\left(1+r_{\varepsilon}\right)\left(1-r_{\sigma}\right)^{a-2}\right] f\left(r_{\sigma}\right)}{(a-1)\left(1+r_{\varepsilon}\right)\left(1+r_{\varepsilon} r_{\sigma}\right)\left[r_{\sigma}^{a-2}+\left(R_{90}+R_{0} r_{\sigma}^{a-2}\right)\left(1-r_{\sigma}\right)^{a-2}\right]} \\
& +\frac{(a-1) n-1}{(a-1)\left(1+r_{\varepsilon}\right)} .
\end{aligned}
$$

For the right hand side of the FLD

$$
\begin{aligned}
\varepsilon^{*}= & \frac{\left(1+R_{0}\right)\left[r_{\sigma}^{a-2}+R_{90}\left(1-r_{\sigma}\right)^{a-2}\right] f\left(r_{\sigma}\right)}{(a-1)\left(1+r_{\varepsilon} r_{\sigma}\right)\left[r_{\sigma}^{a-2}+\left(R_{90}+R_{0} r_{\sigma}^{a-2}\right)\left(1-r_{\sigma}\right)^{a-2}\right]} \\
& +\frac{(a-1) n-1}{(a-1)\left(1+r_{\sigma} r_{\varepsilon}\right)},
\end{aligned}
$$

where $R_{0}$ and $R_{90}$ are the ratio of transverse strain to thickness strain under uniaxial tension along the rolling direction and the transverse direction, respectively. $\varepsilon^{*}$ is the ultimate strain in uniaxial tensile test, $r_{\varepsilon}$ and $r_{\sigma}$ are strain ratio and stress ratio, respectively. ' $n$ ' is the strain hardening index and 
' $a$ ' is exponent in Hosford's yield criterion ( $a=8$ for $f c c$ metals) and

$$
f\left(r_{\sigma}\right)=\frac{1}{\left[R_{90}\left(1+R_{0}\right)\right]^{\frac{1}{a}}}\left[R_{90}+\frac{R_{0}}{r_{\sigma}^{a}}+\frac{R_{0} R_{90}}{\left(1-r_{\sigma}\right)^{a}}\right]^{\frac{1}{a}} .
$$

The instability occurs at $d \sigma / d \varepsilon=\sigma$, by solving which the condition for the ultimate strain for the constitutive law

$$
\sigma_{y}=K\left(\varepsilon^{p}+\varepsilon_{0}\right)^{n} \text { is } \varepsilon^{*}=n .
$$

The ultimate strain i.e. $\varepsilon^{*}$ is calculated by substituting the values obtained from the simulation in (9) and compared with (11). The error and \% error in ultimate strains are computed and presented in table 5 .

It is seen that the error is within the range of $\pm 10 \%$ and the values from the simulation have been found to tally with those calculated from the analytical formulae. It shows that the proposed method adopted for finding out limit strains is sufficiently accurate and treated to be validated.

Experimental results of Graf and Hosford $(1993,1994)$ showed that changes in strain path during deformation change the forming limits which differ from those obtained from linear strain paths. As a remedy to the variation of FLC with the variation of strain path, stress based forming limit curves called as forming stress limit curves (FSLC) were proposed by Marin et al (1953), Gronostajski and Zimniak (1984) and Arrieux (1995). Stoughton (2000) made a convincing case for the use of FSLC. He assumed a constitutive model with isotropic hardening and then transformed the FLC into principal stress space. He also showed that the FLCs of the as-received sheet and the pre-strained sheet were mapped to a nearly coincidental curve in principal stress space. That is, there exists, within the scope of the assumptions made and within the limits of experimental uncertainty, a single curve that represents the limit of formability of the sheet. This FSLC is then geared towards predicting the onset of necking in sheet metal that is subjected to nonlinear load paths. A theoretical basis for the FSLC was provided by Stoughton and Zhu (2004) who started with theoretical models for FSLC and demonstrated a path independence in stress space. Stoughton and Yoon (2005), proposed FSLCs that account for the orientation dependence of strength. Even though the stress based limit curve obtained is considered having good accuracy as an intrinsic curve that defines the forming limit independent of the strain paths, the limit curves, in stress space, are nearly coincidental because of the lack of sensitivity of the stress-strain relationship at sufficiently large strains. Stoughton (2000) addressed this by showing that when the FLC of Al 2008-T4 was shifted by about $10 \%$, the FSLC was shifted by about $5 \mathrm{MPa}$. Hence FSLC for Nimonic C-263 alloy is plotted and presented in figure 12 .

The data in figure 12 clearly demarcates the safe and unsafe regions for forming. While the data in figure 11 show the region for safe and unsafe deformation based on strain (minor and major strain), the data in figure 12 show the same in terms of stress (limiting minor stress and limiting major stress).

\section{Summary}

As one of the important measures of drawability is the limit strains, the limit strains of Nimonic C-263 alloy are obtained and presented in this paper. Unlike the general method for obtaining limit strains, authors proposed a simpler method to find out the limit strains by simulation. Using the method, the limit strains are found out and the corresponding forming limit diagram plotted. The method is validated with the analytical formulae developed using vertex theory. As the limit strains change with the strain paths, some of the researchers rely upon the forming stress limit curves which are independent of strain paths. Hence, the forming stress limit curve for this alloy is also plotted.

\section{Acknowledgements}

The authors are grateful to Shri M. Raghavaiah, Former General Manager, Midhani, for his help in procuring the experimental alloy sheet. Sincere thanks are due to $\mathrm{Dr}$ G Malakondaiah, Director, DMRL for his permission to use the facilities at DMRL. The authors would like to thank Dr K S Prasad and Dr A K Singh for conducting optical micrography and texture analysis. The authors also would like to thank Shri D S K Murali and Shri R Sekhar Babu for the help in the conduct of tensile testing at DMRL.

\section{References}

Arrieux R 1995 J. Mater. Proc. Technol. 5347

ASTM Standard E-8 2004 Standard test method for tension testing of metallic materials

Atkins A G 1996 J. Mater. Proc. Technol. 56609

Barlat F and Lian J 1989 Int. J. Plasticity 551

Barlat F, Lege D J and Brem J C 1991 Int. J. Plasticity 7693

Bradley E F 1988 Superalloys - A technical guide ASM International. ISBN 0-87170-327

Belytschko T, Lin J and Tsay C S 1981 ASME 48209

Belytschko T, Lin J and Tsay C S 1984 Comp. Meth. Appl. Mech. Eng. 42225

Boudeau N and Gelin J C 1992 J. Mater. Proc. Technol. 32521

Dieter G E 2001 Mechanical metallurgy (London: McGraw Hill Book Co.)

Donachie M J 1984 Superalloys source book ASM International, Material Park

Eyckens Philip, Bael Albert Van and Houtte Paul Van 2009 Int. J. Plasticity 252249

Geng L and Wagoner R H 2002 Int. J. Mech. Sci. 44123

Graf A and Hosford W F 1993 Met. Trans. 24 2497, 2503

Graf A and Hosford W F 1994 Int. J. Mech. Sci. 36897

Gronostajski J and Zimniak Z 1984 J. Metal Working Tech. 10349

Gronostajski J and Zimniak Z 1995 J. Mater. Proc. Technol. 55213 
Hallquist Jhon O 1998 LS-DYNA Theory manual Livermore Software Tech. Corp., California

Hashiguchi K and Protasov A 2004 Int. J. Plasticity 201909

Hematian Jamal 2000 Finite element modeling of wrinkling during deep drawing of pressure vessel end closures (PVECs), MS Thesis, Queen's University Kingston, Ontario, Canada

Hiwatashi Shunji, Bael Albert Van, Houtte Paul Van and Teodosiu Cristian 1998 Int. J. Plasticity 14647

Jie M, Cheng C H, Chan L C, Chow C L and Tang C Y 2007 J. Eng. Mater. \& Technol. 129151

Keeler S P and Backofen W A 1964 ASM Trans. Quart. 5625

Kikuma T and Nakazima K 1971 Proc. ICSTIS Suppl. Trans. ISIJ 11827

Marciniak Z and Kuczynski K 1967 Int. J. Mech. Sci. 9609

Marin J, Hu L W and Hamburg J F 1953 Trans. ASM 45686

Mclean M, Webster G A, Nabarro F R N and Cottrell A 1995 Trans. R. Soc., London 351419

Nakazima K, Kikuma T and Hasuka K 1968 Yawata Technical Report, No. 264, 8530
Richard J A and Richard L K 2006 Adv. Mater. Proc. 16419 Savoie J, Jain M, Carr A R, Wu P D, Neale K W, Zhou Y and Jonas J J 1998 Mater. Sci. \& Engg. A257 128

Sims C T, Stoloff N S and Hagel W C 1987 Superalloys II (New York: John Wiley and Sons)

Singh A K, Saha G G, Gokhale A A and Ray R K 1998 Metall Mater. Trans. A29 665

Storen S and Rice J R 1975 J. Mech. Phys. Solids 23421

Stoughton T B 2000 Int. J. Mech. Sci. 421

Stoughton T B 2001 ASME J. Eng. Mater. Technol. 123417

Stoughton T B and Yoon J W 2005 Int. J. Mech. Sci. 471972

Stoughton T B and Zhu X 2004 Int. J. Plasticity 201463

Toth L S, Gillormini P and Jonas J J 1988 Acta Metall. 363077

Wu P D, Neale K W and Vander Giessen E 1997 Proc. R. Soc. London A453 1831

Yoon J W, Barlat F, Robert E D, Kwansoo C and Tae J Kang 2004 Int. J. Plasticity 20495

Zhu X, Weinmann K and Chandra A 2001 J. Eng. Mater. Technol. 123329 